\title{
Entering the Web-2 Edmodo World to Support Learning: Tracing Teachers' Opinion After Using it in their Classes
}

\author{
http://dx.doi.org/10.3991/ijet.v9i1.3018 \\ M. Batsila ${ }^{1}$, Ch. Tsihouridis ${ }^{2}$, D. Vavougios ${ }^{2}$ \\ 1 The Open University, Milton Keynes, United Kingdom \\ ${ }^{2}$ University of Thessaly, Volos, Greece
}

\begin{abstract}
The main purpose of the present paper is to detect teachers' opinion on the Web 2-Edmodo tool in their classrooms. A number of 41 teachers of various disciplines participated in the research answering a relevant questionnaire. The results revealed that Edmodo is used quite frequently, and though teachers are concerned with its excessive use by their students, they think it is very motivating for learners, they believe it supports their work, they like most of its features and would definitely recommend it to other colleagues.
\end{abstract}

Index Terms-Edmodo- e-learning, ICT applications, K12 social network, Web-2 tools

\section{INTRODUCTION}

The rapid development of new information and communication technologies and their penetration in the processes of production, work, communication and culture bring about radical changes in all areas of human action. The need to acquire a higher level of education and training, so that one can follow the rapid pace of technological change, adapt and be adapted to the new environment, creates new data at all levels of education. The creation of a so-called "knowledge society", a society which is more dependent than ever on knowledge, which becomes a dominant strategy choice, marks an important development in education and plays a central role in this effort, is attributed to new information and communication technologies [8].

Research findings reveal that Information and Communications Technology plays an important role in enabling teachers and students to enhance the educational level and communicate with one another across the globe. This is because they break down borders and barriers at a faster rate than is possible in physical terms, offering authentic material and vast resources for all skills and a valuable tool to enhance teaching and learning [3],[1]. More specifically, for teachers, ICT is a professional resource, a mode of classroom delivery while for learners ICT provides opportunities to communicate more effectively[6],[2].

The use of ICT tools promotes interactive lessons and strongly encourages e-learning among pupils [13],[11]. Research shows that ICT makes classes more vivid, pleasant and appealing to students, leads to learner interaction, engaging them in a wide range of communicative tasks. The use of Hypermedia provides the language teacher and learner with multimedia resources, such as sound, animation and video linked together [10],[9]. Mainly though, it offers an authentic learning environment, and a lot of opportunities for skills practice. Computer-assisted language learning (CALL) environments are both plausible and effective in improving students' communicative abilities [14],[4]. The digital environment School 2.0 improved students' communicative skills and the audiovisual competence [12]. Computer assisted instruction and internet-Based Communication enhanced learners' communicative skills and promoted their motivation and information and communication technology curriculum integration offers powerful tools to enhance language learning, in terms of flexibility, mobility and interaction, offering innovation in the teaching and learning processes [7]. Moreover, the blend of ICTs, stories, games and audiobooks has appealed to the students and gave them an enjoyable experience of a listening lesson [8],[5].

\section{Rationale of the Present Study as to the METHOD AND THE TOPIC CHOSEN}

Over the years, learners have familiarized themselves with the latest computer applications, being attracted to their better design, facility of use and immense capabilities. Therefore, the "technological" learners of today are mechanically oriented, they know how to use technological tools without even formal instruction, enjoy using electronic devices for instance, obtain much of their information electronically or they like ICT integrated learning activities. Moreover, they would like to learn everything via a computer, they spend much of their time on the computer or playing video games, they know how to work with and use software and hardware, they interact and communicate with others via e-mail and/or the internet, they understand how to integrate various technologies. Thus, applications such as, social media, forums and so on have appeared in the teaching environment to meet with learners' interests and the demands of today's linguistic needs.

Among ICT applications, a contemporary well-known e-learning environment is Edmodo. Edmodo is a Web 2.0 tool that allows teachers work with their learners in real time, and can be used either in class or at home. It is a social learning site for classrooms, which does not require an e-mail address on behalf of the learners. Students can be approached only by the teacher or the person who has their group code, thus being safe and secure in its use. Moreover, parents are able to have a code of their own, 
thus being allowed to check and/or work together with young learners and at the same time ensuring that learners' interaction among their peers is safe.

Driven by Edmodo's aforementioned extensive use and our interest to find more about it in the educational reality of the research area, we decided to investigate the frequency of its use as a teaching tool in the classrooms of Secondary Education as well as teachers' opinion about it.

\section{RESEARCH QUESTIONS}

Our basic research question is what teachers of Junior High Schools in the research area think of Edmodo as a teaching tool to assist learning. Conducting our research mainly with a quantitative method, the research questions are as follows: 1. How often is Edmodo used as an instructive tool in teachers' classes? 2. What is teachers' opinion on its features? 3. What is teachers' opinion on the disadvantages of Edmodo? 4. What is teachers' overall opinion of Edmodo as a teaching tool?

\section{THE RESEARCH}

\section{A. The Sample}

A number of 41 teachers (28 women and 13 men) participated in this research. All teachers worked in public Junior High schools of Secondary Education and had a teaching experience of 9 to 23 years. The majority of the teachers taught foreign languages (English, French, German (24), while 7 of them taught modern Greek, 3 of them taught geography, 1 taught maths, 2 teachers taught history and 4 of them taught Information Technology. After all teachers had been explained the purpose of the research and had agreed to participate in it, they were given an anonymous questionnaire to answer. All questionnaires were delivered in the schools premises and teachers answered them during their free school hours, without this procedure impeding their lessons.

\section{B. The research tools}

As mentioned above, teachers' views were recorded on a questionnaire, which included closed type questions graded on the Likert scale, which is the simplest and most widespread one. This scale is used during social and pedagogical researches and provides us with the level and the extent to which the participants agree with a certain view from 1 (e.g. strongly disagree) to 5 (e.g. strongly agree). Upon completion of the questionnaires short follow up interviews were conducted with the teachers in order to shed some more light and details into their answers. Last, the research data were recorded, analyzed and the results are being discussed further down.

\section{Short description of the questionnaire}

The purpose of the questionnaire was to collect data about Edmodo and particularly, regarding the frequency of its use, its environment, its features, its easiness of use, its negative points and teachers' overall impression of it. The questions included in it referred to the following:

- How often teachers use Edmodo in their classes

- How easy they find it

- How they rate its environment

- How motivating they think it is for learners
- How much they think it supports their work in class

- How they rate its features, such as a) marking in real time, b) library, c) calendar, d) on line assignments, e) links to other web sites, f) message posting, g) quizzes, h) on line interactions, i) text and mail, j) assessing learners

- The extent to which they have encountered problems such as a) excessive use by learners, b) learners forgetting their code, c) learners giving the group code to outsiders, d) limited student activities, e) parents disapproval and lack of support, f) lack of consent by school authorities

- What they think of it

- Whether they would recommend it to other colleagues.

However, prior to the questionnaire delivery, teachers were observed by the researchers, as they engaged in the use of Edmodo with the learners in their classes. The note taking of the researchers was followed by informal interviews in order to enhance the understanding of the teachers' practices and form an opinion on the activities used.

\section{DATA ANALYSIS}

The participant teachers gave answers to the aforementioned questions. The data which resulted from these answers were analyzed and the results are discussed further down in the form of diagrams.

As a general rule, every study (or every measurement, or every evaluation) involves a number of experimental/research errors and therefore, the present study cannot be an exception. Such errors can be finally folded into a single numerical value (one for every data point) called measurement errors. Every experimentalresearch point measured is (in general) only valid within the limits of the experimental-research errors. This is true for every research study. While during the data-taking phase of the present study an emphasis was paid in minimizing biases and avoiding large systematic errors. During the data analysis an effort was paid into evaluating these, which after due consideration, were set at $2.0 \%$ flat, a figure, which is comparable with all our statistical errors, and not dominated by them. All relevant statistics were calculated using specially constructed software, interfaced with a popular computational and plotting package. The statistical error was calculated for each and every point of the dataset taken, as this is a function of the sample taken and it varies according to the actual given by the students. The statistical variance was computed and the Bessel-corrected standard deviation was calculated for all data points presented. The total experimental/research error was then calculated by adding in quadrature the systematic with the statistical errors, these two errors being by definition independent.

\section{Results}

The results of the analysis of the questionnaires are herein presented, in the form of figures, on which the error 
bars (the meaning of which is explained above) are also denoted.

Question 1: How often do you use it in class?

A percentage of $48.8 \%( \pm 7.90 \%)$ teachers answered that they use Edmodo three times a week, while $19.5 \%$ $( \pm 6.27 \%)$ of them use it twice a week, $14.6 \%( \pm 5.59 \%)$ of them use it once a week, $9.8 \%( \pm 4.69 \%)$ of the teachers do not use it at all, while only $7.3 \%( \pm 4.12 \%)$ of them use it 4 or five days per week. Figure 1 shows the percentage of teachers regarding question 1 .

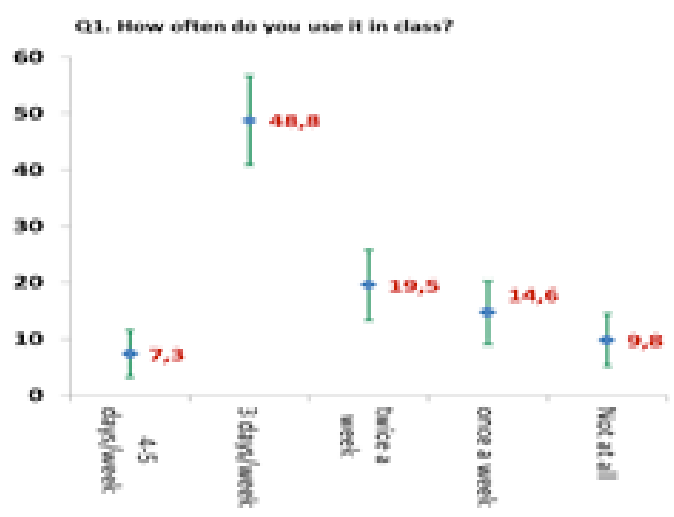

Figure 1. How often do you use it in class?

Question 2: How easy do you find it?

A percentage of $43.9 \%( \pm 7.85 \%)$ teachers' answers about the easiness of use was neutral, while $29.3 \%$ $( \pm 7.19 \%)$ of them said it is quite easy, $12.2 \%( \pm 5.17 \%)$ teachers answered fair, $9.8 \%( \pm 4.69 \%)$ of the teachers said it is very easy, while a percentage of $4.9 \%( \pm 3.41 \%)$ of the teachers said it is not easy at all. Figure 2 shows the percentage of teachers regarding question 2 .

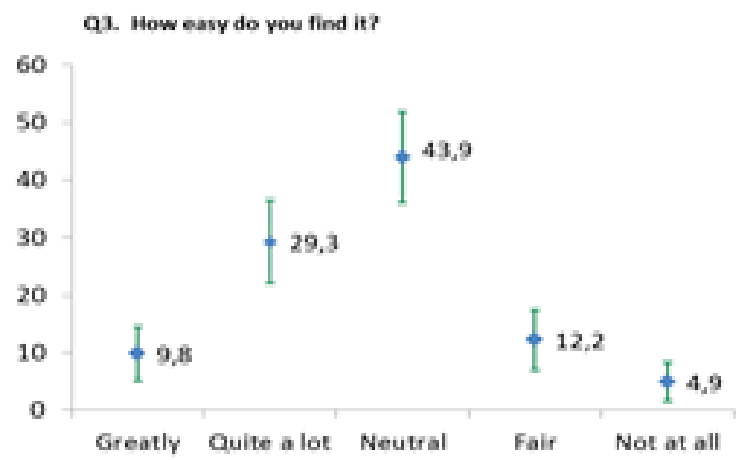

Figure 2. How easy do you find it??

Question 3: How would you rate its environment?

A percentage of $36.6 \%( \pm 7.62 \%)$ teachers answered it is very good, while $29.3 \%( \pm 7.19 \%)$ of them said it is excellent, $22 \%( \pm 6.54 \%)$ said it is good, $7.3 \%( \pm 4.12 \%)$ think it is fair, while a percentage of $4.9 \%( \pm 3.41 \%)$ teachers believe it is poor. Figure 3 shows the percentage of teachers regarding question 3 .

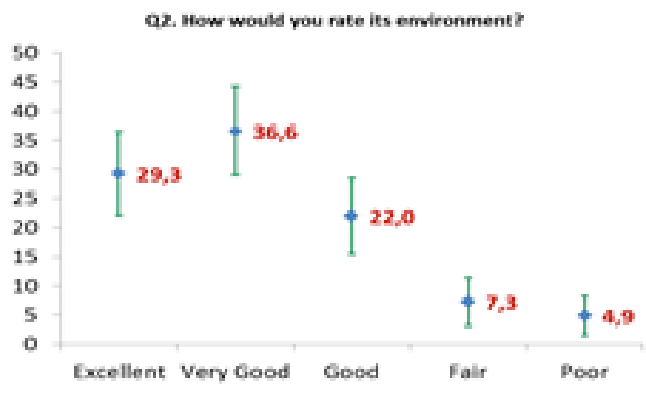

Figure 3. How would you rate its environment?

Question 4: How motivating do you think it is for learners?

A percentage of $31.7 \%( \pm 7.36 \%)$ teachers' answers concerning motivation was quite a lot, while $29.3 \%$ $( \pm 7.19 \%)$ of the teachers answered greatly, $24.4 \%$ $( \pm 6.79 \%)$ of them were neutral, $9.8 \%( \pm 4.69 \%)$ answered fair, and a percentage of $4.9 \%( \pm 3.41 \%)$ answered not at all. Figure 4 shows the percentage of teachers regarding question 4.

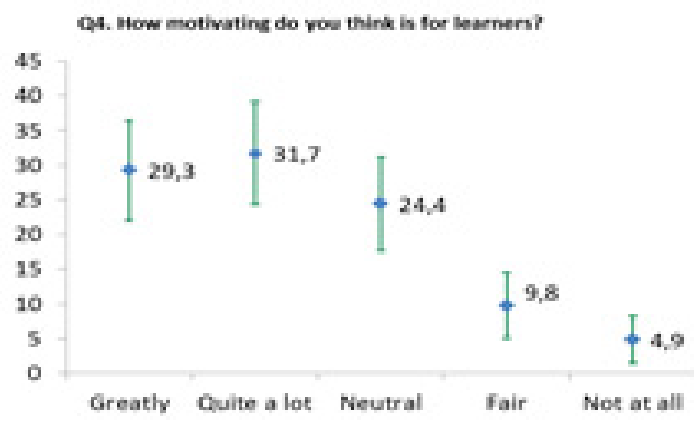

Figure 4. How motivating is it for learners?

Question 5: How much does it support your work in class?

A percentage of $43.9 \%( \pm 7.85 \%)$ teachers believe that it helps them quite a lot, while $22 \%( \pm 6.54 \%)$ think it helps them greatly, $17.1 \%( \pm 5.95 \%)$ answered neutral, $12.2 \%$ $( \pm 5.17 \%)$ answered fair, and a percentage of $4.9 \%$ $( \pm 3.41 \%)$ answered not at all. Figure 5 shows the percentage of teachers regarding question 5 .

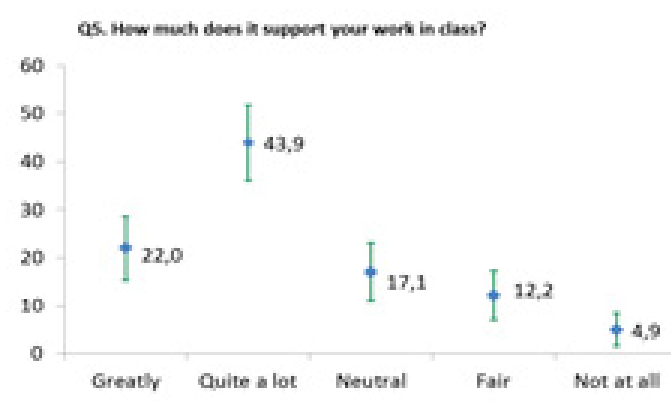

Figure 5. How much does it support your work in class?

Question 6: How would you rate its ability to offer marking in real time?

A percentage of $53.7 \%( \pm 7.88 \%)$ teachers rated its ability to offer marking in real time as very good, while $22 \%( \pm 6.54 \%)$ of them rated it as excellent, $14.6 \%$ $( \pm 5.59 \%)$ rated it as good, $4.9 \%( \pm 3.41 \%)$ rate it as fair, 
and a percentage of $4.9 \%( \pm 3.41 \%)$ rated it as poor. Figure 6 shows the percentage of teachers regarding question 6 .

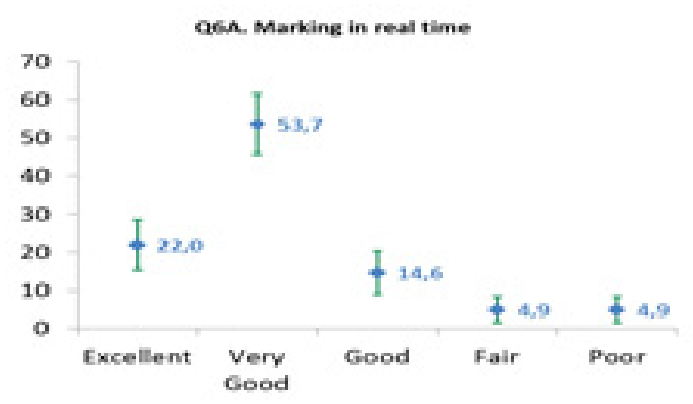

Figure 6. How would you rate its ability to offer marking in real time?

Question 7: How would you rate its library?

A percentage of $53.7 \%( \pm 7.88 \%)$ teachers rated its library as excellent, while $29.3 \%( \pm 7.19 \%)$ of them rated it as very good, $7.3 \%( \pm 4.12 \%)$ rated it as good, $4.9 \%$ $( \pm 3.41 \%)$ rated it as fair, and a percentage of $4.9 \%$ $( \pm 3.41 \%)$ rated it as poor. Figure 7 shows the percentage of teachers regarding question 7 .

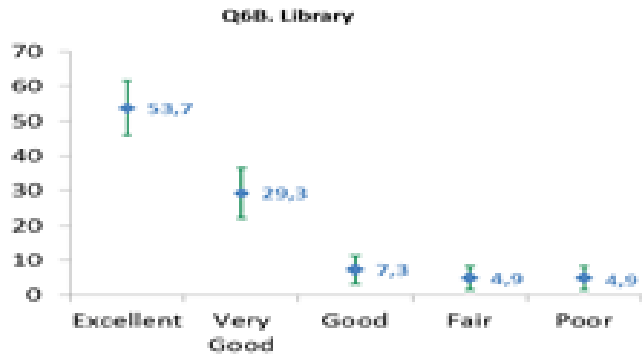

Figure 7. How would you rate its library?

Question 8: How would you rate the on line assignments?

A percentage of $39 \%( \pm 7.71 \%)$ teachers rated the on line assignments as excellent, while $34.1 \%( \pm 7.50 \%)$ of them rated it as very good, $17.1 \%( \pm 5.95 \%)$ rated it as good, $4.9 \%( \pm 3.41 \%)$ rated it as fair, and a percentage of $4.9 \%( \pm 3.41 \%)$ rated it as poor. Figure 8 shows the percentage of teachers regarding question 8 .

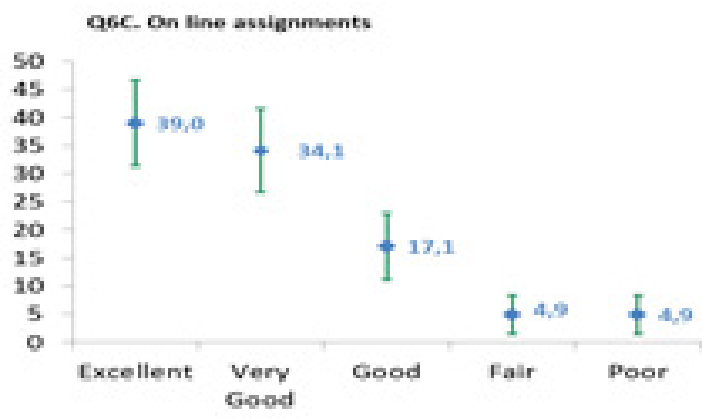

Figure 8. How would you rate the on line assignments?

Question 9: How would you rate the calendar?

A percentage of $36.6 \%( \pm 7.62 \%)$ teachers rated the calendar as good, while $22 \%( \pm 6.54 \%)$ of them rated it as very good, $17.1 \%( \pm 5.95 \%)$ rated it as excellent, $17.1 \%$ $( \pm 5.95 \%)$ rated it as fair, and a percentage of $7.3 \%$
$( \pm 4.12 \%)$ rated it as poor. Figure 9 shows the percentage of teachers regarding question 9.

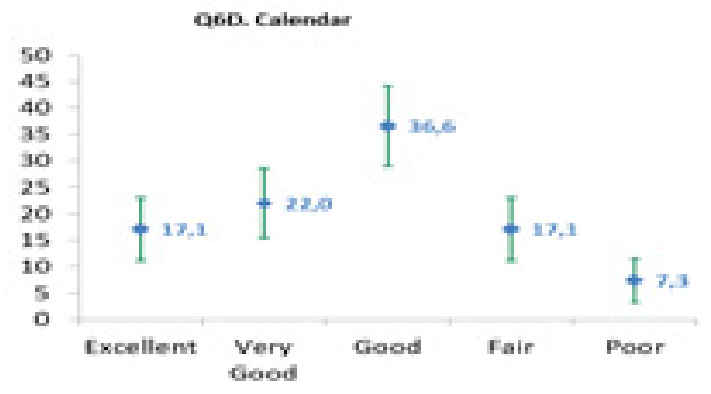

Figure 9. How would you rate the calendar?

Question 10: How would you rate the links to other web sites?

A percentage of $53.7 \%( \pm 7.88 \%)$ teachers rated the links to other web sites as good, while $17.1 \%(5.95 \%)$ of them rated it as very good, $12.2 \%( \pm 5.17 \%)$ rated it as excellent, $9.8 \%( \pm 4.69 \%)$ rated it as fair, and a percentage of $7.3 \%( \pm 4.12 \%)$ rated it as poor. Figure 10 shows the percentage of teachers regarding question 10 .

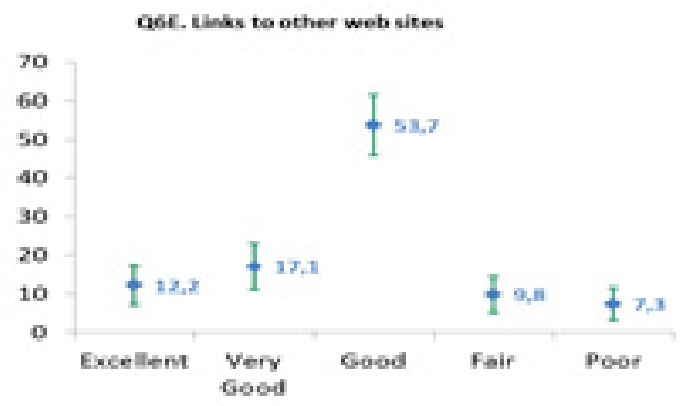

Figure 10. How would you rate the links to other web sites?

Question 11: How would you rate the message posting?

A percentage of $61.0 \%( \pm 7.71 \%)$ teachers rated the message posting as excellent, while $22 \%(6.54 \%)$ of them rated it as very good, $9.8 \%( \pm 4.69 \%)$ rated it as good, $4.9 \%( \pm 3.41 \%)$ rated it as fair, and a percentage of $2.4 \%$ $( \pm 2.44 \%)$ rated it as poor. Figure 11 shows the percentage of teachers regarding question 11 .

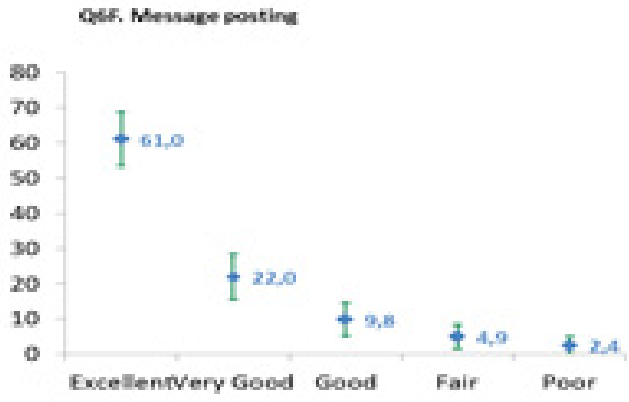

Figure 11. How would you rate the message posting?

Question 12: How would you rate the quizzes?

A percentage of $31.7 \%( \pm 7.31 \%)$ teachers rated the quizzes as excellent, while $29.3 \%(7.19 \%)$ of them rated them as very good, $26.8 \%( \pm 4.69 \%)$ rated them as good, $7.3 \%( \pm 4.12 \%)$ rated them as fair, and a percentage of 
$4.9 \%( \pm 3.41 \%)$ rated them as poor. Figure 12 shows the percentage of teachers regarding question 12 .

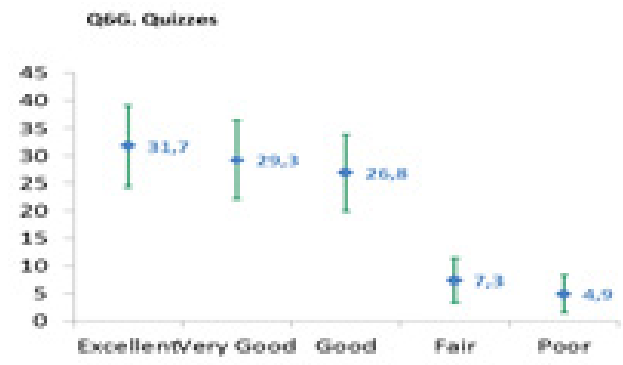

Figure 12. How would you rate the quizzes?

Question 13: How would you rate the on line interactions?

A percentage of $48.8 \%( \pm 7.90 \%)$ teachers rated the on line interactions as excellent, while $24.4 \%(6.79 \%)$ of them rated them as very good, $14.6 \%( \pm 5.59 \%)$ of the teachers rated them as good, $7.3 \%( \pm 4.12 \%)$ rated them as fair, and a percentage of $4.9 \%( \pm 3.41 \%)$ rated them as poor. Figure 13 shows the percentage of teachers regarding question 13 .

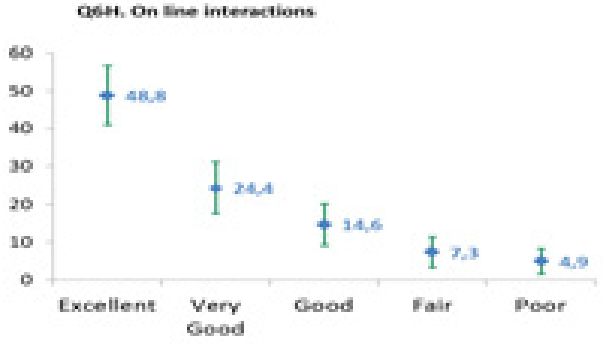

Figure 13. How would you rate the on line interactions?

Question 14: How would you rate text and mail?

A percentage of $41.5 \%( \pm 7.79 \%)$ teachers rated the text and mail as excellent, while $22 \%(6.54 \%)$ of them rated them as very good, $22 \%( \pm 6.54 \%)$ of the teachers rated them as good, $9.8 \%( \pm 4.69 \%)$ rated them as fair, and a percentage of $4.9 \%( \pm 3.41 \%)$ teachers rated them as poor. Figure 14 shows the percentage of teachers regarding question 14 .

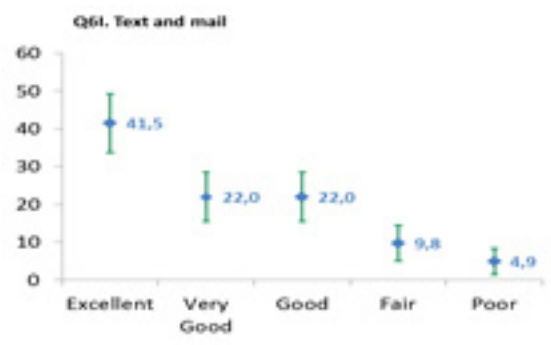

Figure 14. How would you rate text and mail?

Question 15: How would you rate its ability to assess learners?

A percentage of $39 \%( \pm 7.71 \%)$ teachers rated its ability to assess learners as very good, while $22 \%(6.54 \%)$ of them rated it as excellent, $17.1 \%( \pm 5.95 \%)$ rated it as good, $14.6 \%( \pm 5.59 \%)$ rated it as fair, and a percentage of $7.3 \%( \pm 4.12 \%)$ rated it as poor. Figure 15 shows the percentage of teachers regarding question 15 .

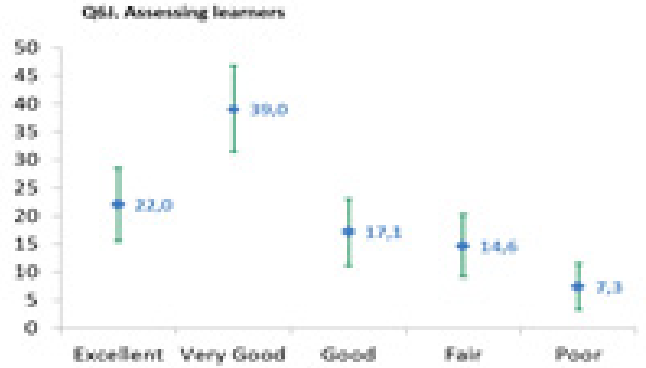

Figure 15. How would you rate its ability to assess learners?

Question 16: To what extent have you encountered excessive use by learners?

In a range from 1 (the least) to 5 (the most), a percentage of $58 \%( \pm 7.79 \%)$ teachers rated the excessive use of Edmodo by learners as 4, while $14.6 \%(5.59 \%)$ of them rated it as 3, 12.2\% $( \pm 5.17 \%)$ of them rated it as 5 , another $4.9 \%( \pm 3.41 \%)$ rated it as 2 , and a percentage of $9.8 \%( \pm 4.69 \%)$ rated it as 1 . Figure 16 shows the percentage of teachers regarding question 16 .

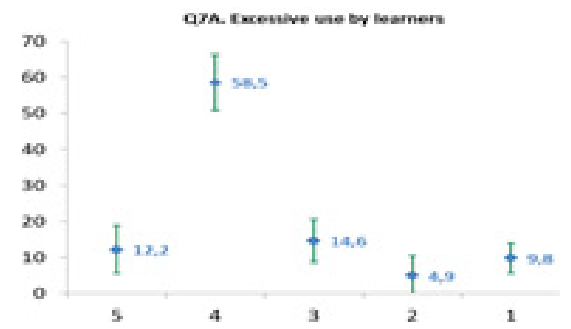

Figure 16. To what extent have you encountered excessive use by learners?

Question 17: To what extent have you encountered learners forgetting their code?

In a range from 1 (the least) to 5 (the most), a percentage of $53.7 \%( \pm 7.88 \%)$ teachers rated the fact that learners forget their code as 3, while $14.6 \%(5.59 \%)$ of them rated it as 4 , another $14.6 \%(5.59 \%)$ of them rated it as 5 , a percentage of $9.8 \%( \pm 4.69 \%)$ rated it as 2 , and another $7.3 \%( \pm 4.12 \%)$ rated it as 1 . Figure 17 shows the percentage of teachers regarding question 17.

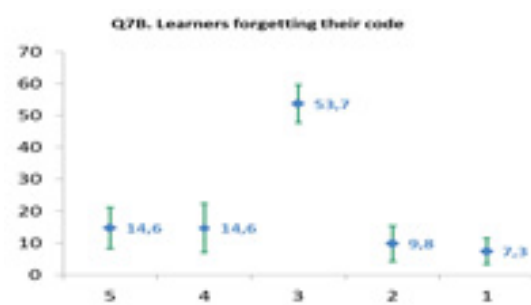

Figure 17. To what extent have you encountered learners forgetting their code?

Question 18: To what extent have you encountered learners giving the group code to outsiders?

In a range from 1 (the least) to 5 (the most), a percentage of $34.1 \%( \pm 7.50 \%)$ teachers rated the fact that learners give the group code to outsiders as 3, while another $34.1 \%(7.50 \%)$ of them rate it as 2 , a percentage of $9.8 \%( \pm 4.69 \%)$ teachers rated it as 5 , another $9.8 \%$ $( \pm 4.69 \%)$ rated it as 4 and a percentage of $12.2 \%$ 
$( \pm 5.17 \%)$ rated it as 1 . Figure 18 shows the percentage of teachers regarding question 18 .

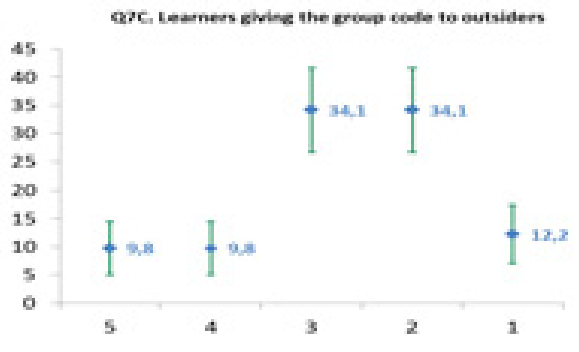

Figure 18. To what extent have you encountered learners giving their code to outsiders?

Question 19: To what extent do you believe there are limited student activities?

In a range from 1 (the least) to 5 (the most), a percentage of $46.3 \%( \pm 7.88 \%)$ teachers believe there are limited student activities as 3, while another $22 \%(6.54 \%)$ of them rated it as 4 , a percentage of $7.3 \%( \pm 4.12 \%)$ teachers rated it as 5, another $17.1 \%( \pm 4.95 \%)$ rated it as 2 and a percentage of $7.3 \%( \pm 4.12 \%)$ rated it as 1 . Figure 19 shows the percentage of teachers regarding question 19.

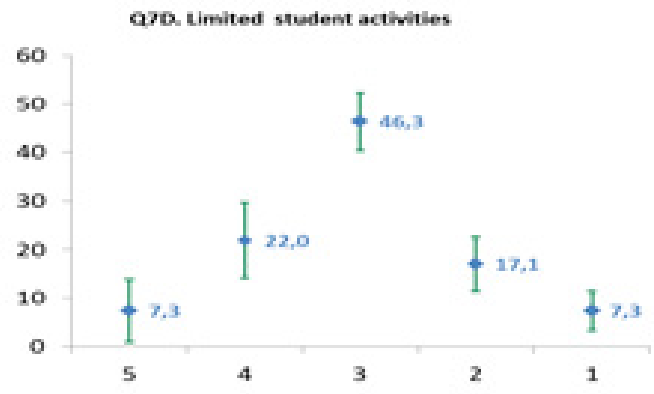

Figure 19. To what extent do you believe there are limited student activities?

Question 20: To what extent have you encountered disapproval and lack of parent support?

In a range from 1 (the least) to 5 (the most), a percentage of $46.3 \%( \pm 7.88 \%)$ teachers rated parents' disapproval and lack of support as 2 , while $29 \%(7.19 \%)$ of them rated it as 3, a percentage of $7.3 \%( \pm 4.12 \%)$ teachers rated it as 4 , another $4.9 \%( \pm 3.41 \%)$ rated it as 5 and a percentage of $12.2 \%( \pm 5.17 \%)$ rated it as 1 . Figure 20 shows the percentage of teachers regarding question 20.

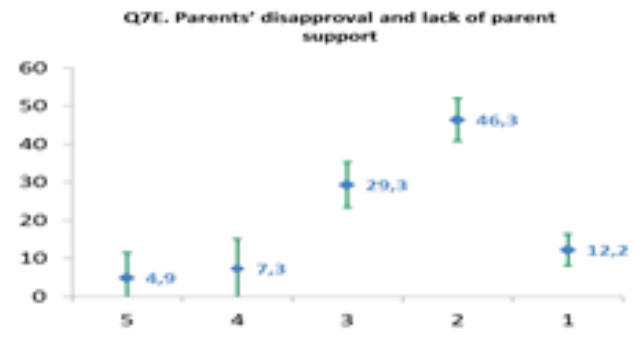

Figure 20. To what extent have you encountered disapproval and lack of parent support?

Question 21: To what extent have you encountered lack of consent by school authorities?
In a range from 1 (the least) to 5 (the most), a percentage of $46.3 \%( \pm 7.88 \%)$ teachers rated lack of consent by school authorities as 2, while $4.9 \%(3.41 \%)$ of them rated it as 5, another $4.9 \%( \pm 3.41 \%)$ rated it as 4 , a percentage of $17.1 \%( \pm 5.95 \%)$ rated it as 3 and $26.8 \%$ $( \pm 7.01 \%)$ of them rated it as 1 . Figure 21 shows the percentage of teachers regarding question 21 .

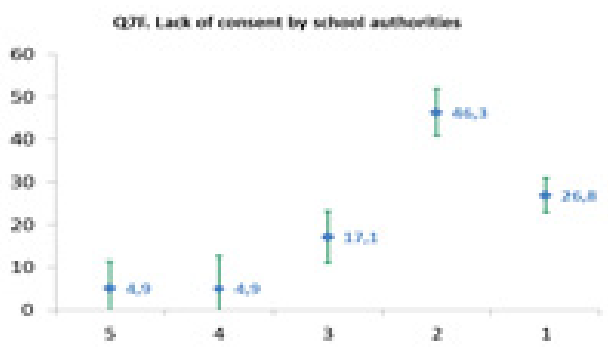

Figure 21. To what extent have you encountered lack of consent by school authorities?

Question 22: What do you think of it?

In a range from 1 (the least) to 5 (the most), a percentage of $43.9 \%( \pm 7.85 \%)$ teachers said it is excellent, while $24.4 \%(6.79 \%)$ of them said it is very good, another $19.5 \%( \pm 6.27 \%)$ said it is good, a percentage of $9.8 \%$ $( \pm 4.69 \%)$ think it fair and $2.4 \%( \pm 2.44 \%)$ of them believe it is poor. Figure 22 shows the percentage of teachers regarding question 22 .

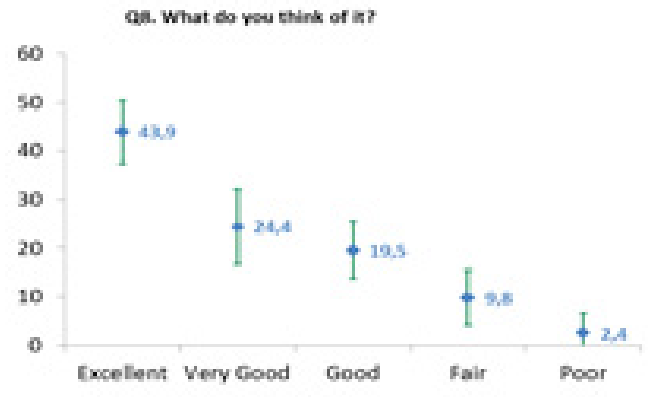

Figure 22. What do you think of it?

Question 23: Would you recommend it to other colleagues?

In a range from 1 (the least) to 5 (the most), a percentage of $26.83 \%(7.01 \%)$ teachers would recommend it with great enthusiasm, while $46.34 \%( \pm 7.88 \%)$ of them said yes, another $14.63 \%( \pm 5.59 \%)$ said they are not sure, a percentage of $7.3 \%( \pm 4.12 \%)$ answered they don't know and $4.88 \%( \pm 3.41 \%)$ of them said they would not recommend it. Figure 23 shows the percentage of teachers regarding question 23 .

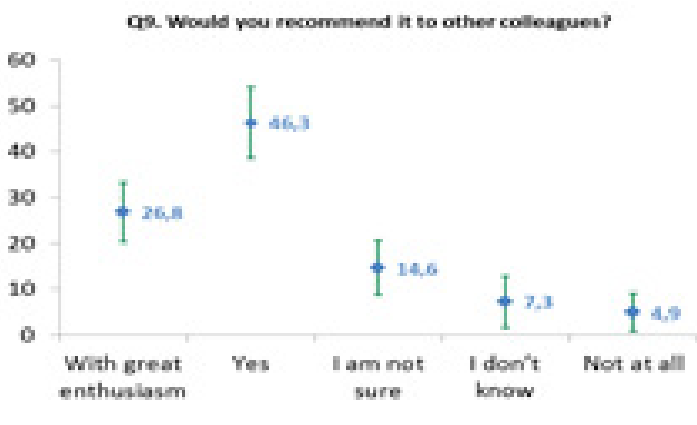

Figure 23. Would you recommend it to other colleagues? 
PAPER

ENTERING THE Web-2 EDMOdo WORLD tO SUPPORT LEARNING: TRACING TEACHERS’ OPINION AFTER USING IT IN...

\section{DISCUSSION AND CONCLUSIONS}

The demands of today have made ICT fundamental in our modern academic and professional world. If we wish to train our learners how to be global citizens and successfully contribute to the development of our society, it is vital to train them accordingly. Thus, the use of ICT seems inevitable and one of the most useful teaching tools for successful implementation of our targets. ICT applications prove to be not only an excellent source of ideas but also one of the most efficient mediums to enhance our learners' educational level, and help them prepare themselves for the skills they need to practice and achieve the goals they have set. Through authentic material and a vast number of resources, ICTs never seize to amaze us through their immense capabilities and assistance to our educational practices.

Using ICT as a classroom tool has many benefits because it provides highly motivated activities for learners. Computer-based activities can provide stimulus to undertake tasks that students may otherwise avoid or be indifferent about. They also link to other learning and to real-world situations and experiences that reflect situations such as cultural diversity. They increase opportunities for student interaction and decision making enhancing an interaction process, which has the potential to cater for individual learning styles. They provide access to resources and increase the need for learners to develop critical thinking and effective information processing skill.

In the present research effort, we focused on a specific application of ICT, Edmodo, which is a social learning platform for teachers and schools. Edmodo is widely used in classes as a subsidiary teaching tool and is thought to be the fastest growing K12 social network in the world. It resembles Facebook, and we could call it the "classroom facebook", due to its secure and safe environment, as the teacher or parent can only have access to the learner groups who interact with the teacher. Our research aimed to investigate the frequency of its use in the classrooms of Junior High Schools in the research area, as well as the teachers' opinion about it.

As concerns the first question the results showed that the majority of the teachers $(48.8 \%( \pm 7.90 \%))$ use it at least three times a week, which seems to be quite frequently. During the follow up conversations with them, they explained that this is due to its ability to motivate learners, a fact which they consider a very important factor for successful learning to take place. Regarding the second question and the easiness of use, a percentage of $43.9 \%( \pm 7.85 \%)$ teachers were neutral, while $29.3 \%$ $( \pm 7.19 \%)$ answered that it is quite easy to use. We believe that the majority of the teachers' answers were neutral due to the fact that, as they mentioned, not all of them had received formal training on Web-2 tools and they were not so familiar with such skills. Concerning question three and its environment, most teachers answered that the Edmodo environment is very good $(36.6 \%( \pm 7.62 \%))$ or excellent $(29.3 \%( \pm 7.19 \%))$. In our conversations they mentioned that compared to other environments they had worked with in the past, they found it more convenient or better organized for both teachers and learners. Regarding question four, most teachers claimed that Edmodo is quite motivating for learners $(31.7 \% \quad( \pm 7.36 \%))$ or very motivating $(29.3 \%( \pm 7.19 \%))$ and they are very enthusiastic about that. As they explained, due to Edmodo use, learners are more participant in their lessons or keen on homework than before and very often urge the teachers to use Edmodo more frequently. In question number 5, teachers confirmed that Edmodo helps them quite a lot $(43.9 \%( \pm 7.85 \%))$ or greatly $(22 \%( \pm 6.54 \%))$ with their work and this seems to be a really encouraging sign for both learning and teaching.

For question number six to fifteen, the majority of the teachers rated the library, the on line assignments, the message posting, the quizzes, the on line interactions and the text and mail as excellent features of the Edmodo elearning environment, while marking in real time was thought as very good and the links to other web sites and the calendar as good features. Based on the aforementioned answers we can say that the features of Edmodo are thought of quite highly on behalf of the teachers who seem to appreciate their use for the design of their activities in their lessons. On the other hand, and as concerns questions sixteen to twenty one and the disadvantages of Edmodo, the majority of the teachers agreed that learners make an excessive use of it, which, according to their comments throughout our conversations, they base it on the fact that learners find it very motivating. Though teachers are very enthusiastic with their learners' interest, they are also worried as students spend too much time using it, leaving out some other school responsibilities. Moreover, they have seen that learners seem to forget their code quite a lot, which at times is rather inconvenient, as they have to give them a new one all over again. However, according to teachers, learners do not seem to give the group codes to outsiders and this seems not only safe but, as they claimed, it creates a sense of mutual trust between them and the learners. Teachers also answered that they are quite satisfied with the activities that Edmodo has to offer. As well, the majority of them seems neither to have any serious problems with parents, as parents seem to support teachers with their decisions towards the use of Edmodo, nor are there any problems with schools authorities. All in all, the majority of teachers seems to like and approve of Edmodo as a teaching tool and would recommend it to other colleagues.

The aforementioned results comply with the bibliography mentioned in the introduction of this paper, concerning the positive effects and benefits of computer integrated activities. Moreover, we believe the results are quite useful, as they give us an insight on the kind of teaching tools we could employ, such as computer-based ones as Edmodo, in order to arouse our learners' interest. As teachers' main concern is to motivate learners and help them feel that knowledge can be fun and not a burden or something boring to them, it is vital to find exciting and interesting ways to vary the teaching methods and keep learners interested in the lesson and active participants. Last, we believe it would be a good idea to investigate how learners themselves experience Edmodo, based on their own preferences, as this, on one hand, would help us design interesting activities, based on their actual learning needs and on the other, help us employ such teaching methods or techniques that the particular e-learning environment can make a difference for learning in the classrooms of today! 


\section{REFERENCES}

[1] Andrews, R. (2003). "Where next in research on ICT and literacies?" English in Education, 37 (3), pp. 2841 http://dx.doi.org/10.1111/j.1754-8845.2003.tb00 603.x

[2] Crystal, D. (2001). Language and the Internet, Cambridge: Cambridge University Press. http://dx.doi.org/10.1017/CBO9781139164771

[3] Directorate General of Education and Culture (2010.). The Impact of New Information Technologies and Internet on the Teaching of Foreign Languages and on the Role of Teachers of a Foreign Language. ICC.

[4] Gomez, M., S. (2010). "Using web resources to support teachers and students with the teaching and practice of listening comprehension". Encuentro 19, (2010), pp. 20-31.

[5] Hutchison, T.,\& Waters, A. (1987), English for Specific Purposes: A Learning Centered Approach. Cambridge: Cambridge University Press, (1987), pp. 7-8. http://dx.doi.org/10.1017/CBO9780511733031

[6] Kress, G. (2003). Literacy in the New Media Age, London: Routledge http://dx.doi.org/10.4324/978020 3164754

[7] Leone, S. (2008). "The use of new technologies in advanced Italian classes". Proceedings of the Emerging Technologies Conference, University of Wollongong, (June 2008), pp.18-21.

[8] Manasreh, M. (2010). "ICT and the Teaching of English in Qatar: Improving Practice Through Action Research H Inquiry". Part of a dissertation: ICT and the teaching of English in Quatar. An initial action research inquiry into the effectiveness of ICT in improving the teaching and learning experience in language classes at a Qatari school.TESOL (2010).

[9] Morrow, K.: "Principles of Communicative Methodology". In K. Johnson and K. Morrow (Eds.), Communication in the Classroom. London: Longman, (1981), pp. 59-66.

[10] Padurean, A., \& Margan, M. (2009). "Foreign Language Teaching Via ICT". Revista de Informatica Sociala. Vol. VII, No 12, (December 2009), pp. 97-101.
[11] Rahimi, M., \& Yadollahi, S. (2006). "ICT Use in EFL Classes: A Focus on EFL Teachers' Characteristics'. World Journal of English Language. (October 2011) Vol. 1, No 2, pp. 17-29.

[12] Rico, A., José, M., M., \& García, M. (2011). “The Use of ICTs to Improve Communicative Skills in a Bilingual Context: an Educational Project of the Spanish Ministry of Education in Melilla”. International Conference: ICT for Language Learning, $4^{\text {th }}$ edition.

[13] Samuel, R, J., \& Zaitun, A., B. (2007). "Do Teachers have Adequate ICT Resources and the Right Skills in Integrating ICT Tools in the Teaching and Learning of English Language in Malaysian Schools?" EJISDC (2007) Vol. 29, No 2, pp.1-15.

[14] Woods, P (1999). “Qualitative research” In: Bird M., Hammersley M., Gomm R. \& Woods P. (Eds), Educational Research in Action - Manual of study, PATRAS: Greek Open University, (1999), pp.147219.

[15] Zhihong, L., Leijuan, H., \& Xiaohui, H. (2010). “A research on a student-centered teaching model in an ICT-based English audio-video speaking class". International Journal of Education and Development using Information and Communication Technology (IJEDICT),Vol. 6, Issue 3, (2010), pp. 101-123.

\section{AUTHORS}

M. Batsila, M.Sc., M. Ed., and Doctoral Research Student, The Open University The Open University, Walton Hall, Milton Keynes, United Kingdom, MK7 6AA (e-mail: marbatsila@gmail.com).

Ch. Tsihouridis, Ph.D., Department of Special Education, University of Thessaly, Argonafton \& Filellinon 8221, Volos, Greece (e-mail: hatsihour@uth.gr).

D. Vavougios, Ph.D., Associate Professor in the Department of Special Education, University of Thessaly, Volos, Argonafton \& Filellinon 38221 Greece (e-mail: dvavou@uth.gr.)

Submitted 18 July 2013. Published as re-submitted by the authors 11 February 2014. 